\title{
Efeito da escória de siderurgia na química do solo e na absorção de nutrientes e metais pesados pela cana-de-açúcar ${ }^{1}$
}

\author{
Luiz Carlos Prezotti ${ }^{2} \&$ André Guarçoni Martins ${ }^{3}$
}

\begin{abstract}
RESUMO
Com a redução das reservas naturais de nutrientes e o alto custo dos fertilizantes, tem aumentado a busca por fontes alternativas, sendo a escória de siderurgia uma opção, uma vez que possui compostos neutralizantes da acidez do solo e elementos químicos importantes para a nutrição das plantas. Este trabalho teve por objetivo avaliar as alterações, nas características químicas do solo e nos teores de nutrientes e de metais pesados, na cana-de-açúcar, em função de doses crescentes de escória de siderurgia. Os tratamentos foram compostos por oito doses de escória de

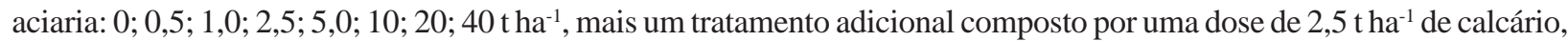
totalizando nove tratamentos, distribuídos em blocos ao acaso, com três repetições. Foram determinadas as características químicas de solo e planta, bem como a produtividade da cana-de-açúcar. A aplicação de escória no solo elevou o $\mathrm{pH}$, a saturação por bases e os teores de $\mathrm{P}, \mathrm{Ca}, \mathrm{B}, \mathrm{Fe}$ e Mn, não influenciando os teores de $\mathrm{K}$ e Mg. Mesmo aplicandose doses mais elevadas, não houve alteração nos teores dos metais pesados $\mathrm{Cd}, \mathrm{Pb}$ e $\mathrm{Ni}$ do solo. Houve elevação do teor de Cr. O teor de $\mathrm{P}$ na folha e no colmo da cana-de-açúcar apresentou tendência de aumento com as doses de escória, não havendo influência para os demais nutrientes, como, também, para os metais pesados. Houve elevação da produtividade tanto da cana-planta como da cana-soca.
\end{abstract}

Palavras-chave: fertilidade do solo, resíduos, reciclagem de nutrientes, Saccharum.

\section{ABSTRACT}

\section{Soil chemical characteristics, nutrients and heavy metal elements in sugar cane crop as function of steel slag doses}

The reduction in natural sources of nutrients and the high cost of fertilizers have increased the search for new compounds for agricultural uses. Steel slag has high lime content and contains other important minerals for plant nutrition. This study aimed to evaluate the effect of increasing doses of steel slag on chemical changes of soil characteristics and on nutrients and level of heavy metals of sugar cane crop. The experiment was arranged in a randomized complete blocks design with three replicates and eight steel slag doses: $0 ; 0.5 ; 1.0 ; 2.5 ; 5,0 ; 10 ; 20 ; 40$ tha${ }^{1}$. An additional treatment with lime $\left(2.5 \mathrm{tha}^{-1}\right)$ was used. Steel slag increased soil $\mathrm{pH}$, basis saturation and the levels of $\mathrm{P}, \mathrm{Ca}, \mathrm{B}, \mathrm{Fe}$ and $\mathrm{Mn}$; no changes on $\mathrm{K}$ and $\mathrm{Mg}$ levels were observed. None of the steel slag used increased level of Cd, $\mathrm{Pb}$ and $\mathrm{Ni}$ in the soil. However, $\mathrm{Cr}$ levels were significantly affected. On leaves and stalk, phosphorus was the only chemical influenced by increasing the doses of steel slag. An improvement of sugar cane productivity was detected.

Key words: soil fertility, residues, nutrients recycle, Saccharum.

\footnotetext{
Recebido para publicação em 12/08/2011e aprovado em 05/07/2012.

${ }^{1}$ Trabalho financiado pela Arcelor Mittal Tubarão.

${ }^{2}$ Engenheiro-Agrônomo, Doutor. Instituto Capixaba de Pesquisa, Assistência Técnica e Extensão Rural (Incaper), Rua Afonso Sarlo-Bento Ferreira, 29052-010, Vitória, Espírito Santo, Brasil. prezotti@incaper.es.gov.br

${ }^{3}$ Engenheiro-Agrônomo, Doutor. Instituto Capixaba de Pesquisa, Assistência Técnica e Extensão Rural (Incaper), Rodovia BR 262, Km 94, 29.278.000, Domingos Martins, Espírito Santo,Brasil.guarconi@incaper.es.gov.br
} 


\section{INTRODUÇÃO}

A redução das reservas naturais de nutrientes e o alto custo da industrialização e do transporte dos fertilizantes e corretivos têm despertado interesse na busca por fontes alternativas de nutrientes. Nesse sentido, as escórias de siderurgia podem ser consideradas importantes opções, uma vez que apresentam compostos neutralizantes da acidez do solo, como silicatos, e nutrientes, como o cálcio, o magnésio e o fósforo, dentre outros.

As escórias são originadas da reação do calcário com a sílica $\left(\mathrm{SiO}_{2}\right)$ presente no minério de ferro, resultando num produto rico em $\mathrm{CaSiO}_{3}$ e $\mathrm{MgSiO}_{3}$. A reação de neutralização da acidez do solo proporcionada pela aplicação da escória ocorre pela dissociação do $\mathrm{CaSiO}_{3}$ e do $\mathrm{MgSiO}_{3}$ em $\mathrm{Ca}, \mathrm{Mg}$ e $\mathrm{SiO}_{3}$, sendo que este último reage com $\mathrm{H}^{+}$da solução do solo formando $\mathrm{H}_{4} \mathrm{SiO}_{4}$, reduzindo assim sua acidez. Assim como o calcário, a reatividade da escória varia conforme a granulometria, a dosagem e o tempo de contato com o solo. O silicato de cálcio é 6,78 vezes mais solúvel que o carbonato de cálcio, presente nos calcários (Alcarde, 1992).

Estudos realizados por Prado \& Fernandes (2000 e 2003) demonstraram que a escória, quando aplicada ao solo, aumenta o $\mathrm{pH}$ e reduz o $\mathrm{H}+\mathrm{Al}$. Incrementos na disponibilidade de $\mathrm{P}, \mathrm{Si}, \mathrm{Ca}, \mathrm{Mg}$ foram observados por Prado et al. (2003). De acordo com Coelho (1998), gera-se, em média, uma tonelada de escória de alto forno para cada quatro toneladas de ferro-gusa produzidas.

O Brasil é o sexto maior produtor mundial de ferro-gusa, com produção anual de cerca de 25 milhões de toneladas, $\mathrm{o}$ que corresponde à geração de cerca de 6,25 milhões de toneladas de escória por ano. Minas Gerais é o maior produtor brasileiro, responsável por mais da metade de todo o ferro-gusa e do aço produzidos nacionalmente.

O Brasil pouco utiliza a escória na agricultura, ao contrário dos Estados Unidos, Japão e China (Prado et al., 2003). Em razão da grande quantidade produzida e da falta de destinação para as escórias, as siderúrgicas são obrigadas a estocá-las em pátios, ocupando grandes áreas. $\mathrm{O}$ acúmulo desses materiais nesses locais tem-se tornado um sério problema ambiental, pela possibilidade de lixiviação de compostos químicos, ocasionada por exposição às chuvas, podendo ocorrer contaminação do lençol freático.

O objetivo deste trabalho foi avaliar o efeito da escória de siderurgia nas características químicas do solo, na absorção de nutrientes e de metais pesados e na produtividade da cana-de-açúcar, cultivada num Latossolo Vermelho-Amarelo distrófico.

\section{MATERIAL E MÉTODOS}

O trabalho foi realizado com a cultura da cana-de-açúcar, variedade RB 75-8540 (Saccharum spp L.), na locali- dade de Morro Seco, distrito de Burarama, município de Cachoeiro de Itapemirim, ES.

A área experimental está localizada em altitude de 120 $\mathrm{m}$, nas coordenadas geográficas de $20^{\circ} 44^{\prime} \mathrm{S}$ e $41^{\circ} 18^{\prime} \mathrm{O}$. O relevo é ligeiramente plano, com ondulações, e o solo foi classificado como Latossolo Vermelho-Amarelo distrófico $\left(\right.$ LVA $\left._{d}\right)$. Foi selecionada uma área de pastagem de Brachiaria brizantha cv. Marandu, onde foram implantadas as unidades experimentais.

Os tratamentos consistiram em oito doses de escória de siderurgia $\left(0,0 ; 0,5 ; 1,0 ; 2,5 ; 5,0 ; 10,0 ; 20,0\right.$ e 40,0 t ha $\left.^{-1}\right)$ e uma dose de $2,5 \mathrm{t}$ de calcário ha $^{-1}$, totalizando nove tratamentos, distribuídos em delineamento experimental de blocos ao acaso, com três repetições. As parcelas experimentais constituíram-se de quatro linhas de plantio de cana-de-açúcar de quatro metros de comprimento, espaçadas de 1,40 m, sendo consideradas como bordaduras as duas linhas laterais e meio metro de cada extremidade das linhas úteis.

As amostras de escória foram coletadas no pátio de estocagem da Siderúrgica Arcelor Mittal Tubarão, no município de Serra-ES, e peneiradas em malha de $2 \mathrm{~mm}$. Os teores de nutrientes e de metais pesados da escória e do calcário foram determinados, segundo metodologia descrita por Embrapa (1999), utilizando-se 0,5 g de cada amostra em $20 \mathrm{~mL}$ de $\mathrm{HCl} 2 \mathrm{~mol} \mathrm{~L}^{-1}$, mantendo-se fervura, por 5 a 10 minutos, em bloco digestor aberto. As amostras, após resfriadas e filtradas, foram colocadas em balão de $100 \mathrm{~mL}$, completando-se o volume com água destilada. A quantificação dos elementos nos extratos foi feita em espectrofotômetro de absorção atômica. Os dados são apresentados nas Tabelas 1 e 2.

Um mês antes do plantio da cana-de-açúcar, as doses de escória foram aplicadas a lanço sobre toda a superfície das parcelas e incorporadas até $20 \mathrm{~cm}$ de profundidade, utilizando-se trator com enxada rotativa. A adubação com $\mathrm{N}$ e K foi baseada na demanda da cultura e na análise do solo (Prezotti, 2007).

Três meses após a aplicação dos tratamentos, foi realizada a amostragem de folha e de solo das parcelas. A amostragem de solo foi realizada segundo recomendações de Alvarez V \& Guarçoni (2003), e determinados os teores de macro (P, K, Ca e Mg), de micronutrientes ( $\mathrm{Zn}$, $\mathrm{B}, \mathrm{Cu}, \mathrm{Fe}$ e $\mathrm{Mn}$ ) e de metais pesados ( $\mathrm{Cd}, \mathrm{Cr}, \mathrm{Pb}$ e $\mathrm{Ni}$ ) (Embrapa, 2009). Quando as plantas atingiram o ponto de colheita, realizou-se o primeiro corte da parte aérea, determinando-se a produtividade.

Com o objetivo de avaliar o efeito residual da escória, avaliou-se a produção da cana-soca, aplicando-se somente os nutrientes N e K em cobertura, segundo Prezotti (2007).

As amostras de cana-planta e de cana-soca foram separadas em folhas e colmo e determinados os teores de macro (P, K, Ca, Mg e S), de micronutrientes ( $\mathrm{Zn}, \mathrm{B}, \mathrm{Cu}, \mathrm{Fe}$ 
Tabela 1. Teores de macro e micronutrientes parcialmente solubilizados pelo método Embrapa (1999) em dois corretivos da acidez

\begin{tabular}{lrrrrrrrrr}
\hline \multirow{2}{*}{ Produto } & $\mathbf{P}$ & $\mathbf{K}$ & $\mathbf{N a}$ & $\mathbf{C a}$ & $\mathbf{M g}$ & $\mathbf{C u}$ & $\mathbf{F e}$ & $\mathbf{Z n}$ & $\mathbf{M n}$ \\
\cline { 2 - 10 } & \multicolumn{10}{c}{$\mathrm{mg} \mathrm{kg}^{-1}$} \\
\hline Escória & 3.200 & 228 & 216 & 205.200 & 35.600 & 12 & 117.500 & 48 & 19.900 \\
Calcário & 270 & 526 & 58 & 237.600 & 58.400 & 2 & 1.652 & 8 & 52 \\
\hline
\end{tabular}

Tabela 2. Teores de metais pesados parcialmente solubilizados pelo método Embrapa (1999) em dois corretivos da acidez

\begin{tabular}{lcccc}
\hline \multirow{2}{*}{ Produto } & $\mathbf{C d}$ & $\mathbf{C r}$ & $\mathbf{P b}$ & $\mathbf{N i}$ \\
\cline { 2 - 5 } & \multicolumn{4}{c}{$\mathrm{mg} \mathrm{kg}^{-1}$} \\
\hline Escória & 2,6 & 703 & 50 & 37 \\
Calcário & 2,6 & 7 & 40 & 23 \\
\hline
\end{tabular}

e $\mathrm{Mn})$ e de metais pesados $(\mathrm{Cd}, \mathrm{Cr}, \mathrm{Pb}$ e $\mathrm{Ni}$ ) nessas duas frações segundo métodos descritos em Embrapa (2009). O teor de $\mathrm{N}$ não foi avaliado, em razão da sua ausência na constituição da escória de siderurgia.

As variáveis estudadas foram interpretadas estatisticamente por meio das análises de variância e de regressão, utilizando-se o software SAEG - Sistema de Análises Estatísticas e Genéticas (Ribeiro Júnior, 2001). Comparou-se o tratamento de $2,5 \mathrm{t} \mathrm{ha}^{-1}$ de calcário com o seu equivalente de escória, pelo teste de Dunnet $(\mathrm{P}<0,05)$. Para o fator quantitativo (doses de escória de aciaria), os modelos foram escolhidos com base na significância do teste $\mathrm{F}(\mathrm{P}<0,05)$ para o coeficiente de determinação $\left(\mathrm{R}^{2}\right)$.

\section{RESULTADOS E DISCUSSÃO}

As equações de regressão das características químicas do solo coletado três e seis meses após a aplicação dos tratamentos (cultivo da cana-planta e da cana-soca), em função das doses de escória, são apresentadas na Tabela 3. Verificou-se aumento do $\mathrm{pH}$, da saturação por bases e dos teores de P, Ca, Fe e Mn. Houve acréscimo do teor de $\mathrm{Mg}$, não havendo influência sobre os nutrientes $\mathrm{K}, \mathrm{Zn}, \mathrm{B}$ e Cu. Resultados semelhantes foram encontrados por Prado \& Fernandes (2000) e Prado et al. (2003), os quais constataram um efeito mais expressivo da escória sobre o teor de $\mathrm{Mg}$ do solo.

No cultivo da cana-planta, a partir da dose de $10 \mathrm{t}$ ha ${ }^{1}$, o pH estabilizou-se em valores próximos a 6,6. No cultivo da cana-soca, observou-se uma redução do pH nas menores doses, causada principalmente pela adubação nitrogenada, e aumento do $\mathrm{pH}$, nas maiores doses, indicando efeito residual da escória, em razão da maior quantidade aplicada (Tabela 3).

Não se observou elevação dos teores de P do solo até a dose de 2,5 $\mathrm{t} \mathrm{ha}^{-1}$. A partir dessa dose, a taxa média de acréscimo foi de $2,4 \mathrm{mg} \mathrm{dm}^{-3}$ de $\mathrm{P}$ por tonelada de escória aplicada ao solo, no cultivo da cana-planta, e de 9,6 mg $\mathrm{dm}^{-3}$ de P, no cultivo da cana-soca (Tabela 3 ).
Essa elevação do teor de $\mathrm{P}$ do solo deve-se à presença de fósforo na constituição da escória e à competição do ânion $\mathrm{SiO}_{4}^{-4}$, também presente na escória, pelos mesmos sítios de adsorção do P, o que torna este nutriente mais disponível, corroborando os resultados obtidos por Prado \& Fernandes (1999 e 2001) e por Prado et al. (2003).

A resposta positiva da aplicação da escória sobre o teor de $\mathrm{P}$ do solo é uma das mais importantes vantagens deste insumo, em razão da sua escassez nos solos brasileiros, já fortemente intemperizados e com alta capacidade de fixação deste nutriente. A ação do $\mathrm{SiO}_{4}{ }^{-4}$ da escória, obstruindo os sítios de adsorção das argilas e dos óxidos de Fe e Al, aliada ao P presente na sua constitui-

Tabela 3. Equações de regressão de estimativa do $\mathrm{pH}, \mathrm{P}$ (mg dm$\left.{ }^{3}\right), \mathrm{Ca}$ e $\mathrm{Mg}\left(\mathrm{cmol}_{\mathrm{c}} \mathrm{dm}^{-3}\right), \mathrm{V}(\%)$ e dos micronutrientes B, Fe e Mn $\left(\mathrm{mg} \mathrm{dm}^{-3}\right)$ no período de cultivo da cana-planta e da cana-soca em função de doses de escória de siderurgia (DE)

\begin{tabular}{|c|c|}
\hline Cana-planta & $\mathbf{R}^{2}$ \\
\hline$\hat{p H}=5,8373+0,3232 D E^{1 / 2}-0,03286 D E$ & $0,85^{(0,80)}$ \\
\hline$\stackrel{P}{P}=1,1202+3,5446 D E^{1 / 2}-0,2457 D E$ & $0,87^{(0,60)}$ \\
\hline$\widehat{C a}=1,3097+0,1205 D E-0,002015 D E^{2}$ & $0,67^{(6,37)}$ \\
\hline$\widehat{M g}=0,5075+0,0799 D E^{1 / 2}-0,007804 D E$ & $0,67^{(6,41)}$ \\
\hline$\hat{V}=44,8078+2,7325 D E-0,05361 D E^{2}$ & $0,75^{(3,04)}$ \\
\hline$\widehat{B}=0,1300+0,01938 D E-0,0002538 D E^{2}$ & $0,93^{(0,13)}$ \\
\hline$\widehat{F e}=818885-11020 D E+008816 D E^{2}$ & $0,96^{(0,03)}$ \\
\hline$\widehat{M n}=69,3598+2,5561 D E-0,03649 D E^{2}$ & $0,92^{(0,16)}$ \\
\hline \multicolumn{2}{|l|}{ Cana-soca } \\
\hline$\widehat{p H}=4,7667+0,1254 D E-0,001457 D E^{2}$ & $0,98^{(0,00)}$ \\
\hline$\widehat{P}=2,1737+0,8360 D E-0,005111 D E^{2}$ & $0,99^{(0,00)}$ \\
\hline$\widehat{C a}=0,6921+0,1730 D E-0,002050 D E^{2}$ & $0,98^{(0,01)}$ \\
\hline$\widehat{M g}=0,2658+0,0162 D E-0,000301 D E^{2}$ & $0,67^{(6,20)}$ \\
\hline$\hat{V}=28,400+3,9074 D E-0,06070 D E^{2}$ & $0,97^{(0,02)}$ \\
\hline$\widehat{F e}=33,728+25,288 D E-0,19862 D E^{2}$ & $0,93^{(0,14)}$ \\
\hline$\widehat{M n}=22,188+13,833 D E+0,15811 D E^{2}$ & $0,95^{(0,05)}$ \\
\hline
\end{tabular}

"Valores entre parênteses indicam o nível de significância em percentagem. 
ção, torna este insumo uma excelente alternativa para o aumento da disponibilização desse nutriente em solos tropicais.

Os maiores teores de P no solo, observados no cultivo da cana-soca, provavelmente, devem-se ao maior período de tempo de solubilização da escória, liberando gradativamente o $\mathrm{P}$ retido na estrutura dos minerais presentes na sua constituição. $\mathrm{O}$ aumento da liberação gradativa de $\mathrm{P}$ das escórias, de acordo com o tempo de contato com o solo, foi observado por Silva (2003), que concluiu ser esta uma vantagem da escória frente a outros materiais corretivos.

No cultivo da cana-planta, a escória elevou os teores de $\mathrm{Cr}$ do solo, passando de 0,18 para 0,46 $\mathrm{mg} \mathrm{dm}^{-3}$, sendo que não houve efeito consistente das doses de escória sobre os teores de $\mathrm{Cd}, \mathrm{Pb}$ e Ni (Tabela 4). Entretanto, na amostragem realizada durante o cultivo da cana-soca, observou-se que, além do aumento com as doses crescentes de escória, os teores de $\mathrm{Cr}, \mathrm{Pb}$ e $\mathrm{Ni}$ foram superiores aos determinados durante o cultivo da cana-planta.

À semelhança do que ocorreu com os elementos $\mathrm{P}$, $\mathrm{K}, \mathrm{Ca}, \mathrm{Fe}$ e $\mathrm{Mn}$, é provável que, nas maiores doses de escória, esses metais foram sendo liberados gradativamente, à medida que as partículas dos minerais eram solubilizadas. Na dose zero, e nas menores doses, os maiores teores podem ser atribuídos à redução do $\mathrm{pH}$, ocasionada principalmente pela adubação nitrogenada, o que acarretou maior disponibilização desses metais.

Tabela 4. Teor de metais pesados no solo no período de cultivo da cana-planta e da cana-soca em função de doses de escória de siderurgia

\begin{tabular}{|c|c|c|c|c|}
\hline Dose & Cd & $\mathrm{Cr}$ & $\mathbf{P b}$ & $\mathbf{N i}$ \\
\hline $\mathrm{tha}^{-1}$ & \multicolumn{4}{|c|}{$\mathrm{mg} \mathrm{dm}^{-3}$} \\
\hline \multicolumn{5}{|c|}{ Cana-planta } \\
\hline 0,0 & 0,08 & 0,18 & 0,90 & 0,04 \\
\hline 0,5 & 0,07 & 0,18 & 0,70 & 0,08 \\
\hline 1,0 & 0,07 & 0,14 & 0,80 & 0,01 \\
\hline 2,5 & 0,07 & 0,16 & 0,67 & 0,02 \\
\hline 5,0 & 0,07 & 0,19 & 0,83 & 0,01 \\
\hline 10,0 & 0,10 & 0,40 & 1,13 & 0,03 \\
\hline 20,0 & 0,08 & 0,45 & 0,93 & 0,04 \\
\hline 40,0 & 0,08 & 0,46 & 0,93 & 0,05 \\
\hline \multicolumn{5}{|c|}{ Cana-soca } \\
\hline 0,0 & 0,04 & 0,97 & 1,37 & 0,39 \\
\hline 0,5 & 0,03 & 0,98 & 1,13 & 0,23 \\
\hline 1,0 & 0,04 & 1,22 & 1,13 & 0,48 \\
\hline 2,5 & 0,04 & 1,21 & 1,23 & 0,42 \\
\hline 5,0 & 0,04 & 1,67 & 1,37 & 0,41 \\
\hline 10,0 & 0,05 & 1,53 & 1,37 & 0,51 \\
\hline 20,0 & 0,08 & 2,54 & 1,90 & 0,51 \\
\hline 40,0 & 0,12 & 3,11 & 3,00 & 0,79 \\
\hline
\end{tabular}

Diversos autores (Mazur, 1997; Alcântara \& Camargo, 2001; Dias et al., 2001) mostraram, em seus trabalhos, forte influência da acidez do solo na disponibilidade de metais, sendo esta maior em $\mathrm{pH}$ baixo. Especificamente em relação ao $\mathrm{Cd}$, este efeito não foi observado.

A amplitude de variação dos teores de $\mathrm{Cd}, \mathrm{Cr}, \mathrm{Pb}$ e Ni do solo, considerando-se todos os tratamentos, foi de 0,03 a 0,$12 ; 0,14$ a 3,11; 0,67 a 3,00 e 0,01 a 0,79 $\mathrm{mg} \mathrm{dm}^{-3}$, respectivamente. Esses valores estão próximos dos determinados por Abreu et al. (1995), que, em amostras superficiais de solos do Estado de São Paulo, observaram valores máximos de 1,0;0,0;2,6 e 1,1 $\mathrm{mg} \mathrm{dm}^{-3}$, respectivamente (extrator Mehlich-1). Portanto, mesmo em doses elevadas de escória, como as utilizadas neste trabalho, não se observou elevação importante dos teores disponíveis de metais pesados no solo.

A aplicação de calcário ao solo proporcionou maiores valores de $\mathrm{pH}$ e de saturação por bases, no cultivo da cana-planta, do que a aplicação da mesma dose de escória (Tabela 5). Já na cana-soca, o calcário proporcionou maior teor de $\mathrm{Mg}^{2+}$, maior valor de saturação por bases e menor teor de $\mathrm{Pb}$ do que a mesma dose de escória.

Ressalta-se que a reatividade da escória, assim como a do calcário, varia com a sua granulometria. Neste trabalho, a escória utilizada apresentava tamanho de partículas de até $2 \mathrm{~mm}$. Certamente, se for usada escória de menor diâmetro de partículas, o efeito sobre as características químicas do solo será mais acentuado.

Trabalho realizado por Silva (2003) mostrou que a escória com granulometria inferior a $1 \mathrm{~mm}$ apresentou efeito corretivo da acidez do solo muito superior ao da escória com granulometria entre 2 e $10 \mathrm{~mm}$. Observou também que solos tratados com escória apresentaram teores de $\mathrm{Cd}$ semelhantes ou inferiores aos níveis encontrados nos solos corrigidos com carbonatos, indicando que a escória não promoveu aumento do teor desse elemento no solo, mesmo em doses superiores a $10 \mathrm{t} \mathrm{ha}^{-1}$.

Houve aumento do teor de $\mathrm{P}$ nas folhas, tanto da canaplanta, como da cana-soca (Tabela 6), sendo que na canasoca os teores apresentaram-se em patamares superiores aos dos teores da cana-planta, concordando com os resultados das análises do solo, os quais demonstraram haver maior disponibilidade de $\mathrm{P}$ no período de cultivo da cana-soca.

Os teores de P nas folhas da cana-planta apresentaram tendência de acréscimo, segundo a função quadrática: $\hat{P}_{\text {(Folha) }}=0,1403+0,009113 \mathrm{DE}-0,0007621 \mathrm{DE}^{2}\left(\mathrm{R}^{2}=0,82^{(1,44)}\right)$. Houve pequena influência no teor de $\mathrm{Ca}$ e variações pouco consistentes nos teores dos demais nutrientes. Os teores de metais pesados também foram pouco influenciados pelas doses de escória.

$\mathrm{Na}$ cana-soca, os teores foliares de $\mathrm{P}$ e Ca elevaram-se com as doses crescentes de escória, não sendo observa- 
das alterações consistentes nos teores dos demais nutrientes e dos metais pesados.

Segundo McNichol \& Beckett (1985), citados por Santos (2002), teores acima de $8 \mathrm{mg} \mathrm{kg}^{-1} \mathrm{de} \mathrm{Ni}$, de $4 \mathrm{mg} \mathrm{kg}^{-1}$ de $\mathrm{Cd}$ e de $2 \mathrm{mg} \mathrm{kg}^{-1}$ de $\mathrm{Cr}$ podem ocasionar toxidade em muitas plantas, diminuindo a produção. Para $\mathrm{Pb}$, KabataPendias et al. (1992) consideram o teor de $30 \mathrm{mg} \mathrm{kg}^{-1}$ como sendo o limite de toxidade.

Portanto, observam-se que os teores de $\mathrm{Cd}, \mathrm{Cr}, \mathrm{Pb}$ e $\mathrm{Ni}$, determinados nas folhas de cana-planta e cana-soca, em todos os tratamentos (Tabela 6), situaram-se em níveis inferiores aos limites de toxicidade citados anteriormente.

Não houve diferença entre os teores de nutrientes e metais pesados nas folhas da cana-planta e da cana-soca, nos tratamentos com 2,5 $\mathrm{t} \mathrm{ha}^{-1}$ de escória e de calcário (Tabela 7).
Resultados semelhantes foram obtidos por Silva (2003), que não observou diferenças significativas dos teores de $\mathrm{Cd}$, em plantas de sorgo tratadas com escória e com calcário, nem detectou a presença de $\mathrm{Cr}$ nos tecidos das plantas, em nenhum tratamento.

Análises realizadas no colmo da cana-planta (Tabela 8) mostraram elevação dos teores de fósforo, segundo a função quadrática: $\hat{\mathrm{P}}_{(\text {(Colmo) }}=0,0109+0,00056 \mathrm{DE}-$ $0,0001 \mathrm{DE}^{2}\left(\mathrm{R}^{2}=0,75^{(3,25)}\right)$. Prado \& Fernandes (2001) também observaram relação direta entre as concentrações de $\mathrm{P}$ do solo e a produção de colmos de cana-planta.

A elevação do teor de Ca no colmo seguiu a função quadrática: $\hat{\mathrm{C}} \mathrm{a}_{(\mathrm{Colmo})}=0,0719+0,00071 \mathrm{DE}-0,0001 \mathrm{DE}^{2}$ $\left(\mathrm{R}^{2}=0,69^{(5,42)}\right)$. No caso dos micronutrientes, como o $\mathrm{Zn}$ e Mn, observou-se tendência de redução dos seus teores nas maiores doses. Este fato pode ser atribuído à menor disponibilidade desses elementos, por causa da

Tabela 5. Características químicas do solo em função da dose de 2,5 t ha-1 de escória e de calcário no período de cultivo da cana-planta e da cana-soca

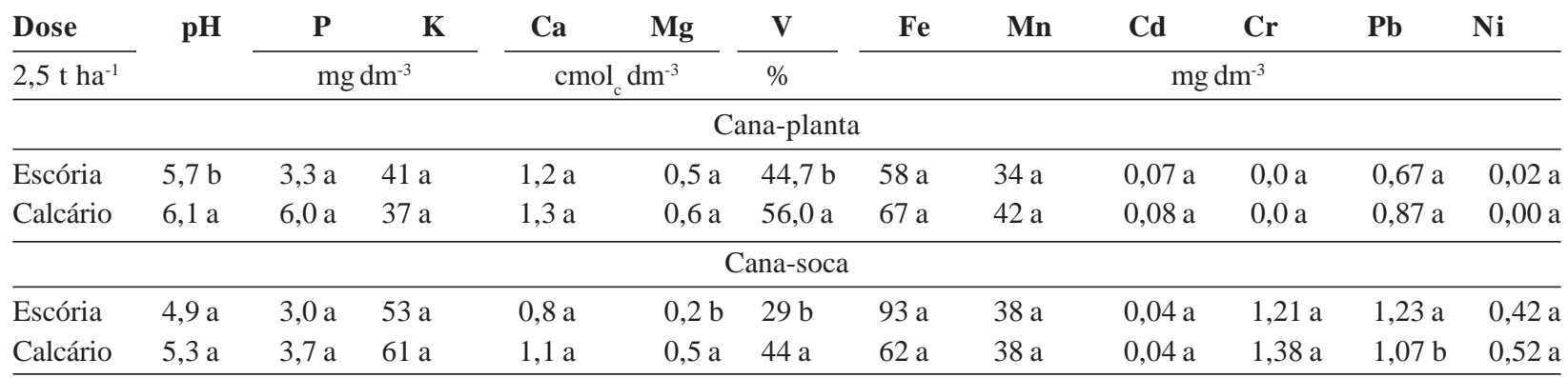

* Médias seguidas pela mesma letra minúscula, na coluna, não diferem entre si pelo teste de Dunnet $(\mathrm{P} \geq 0,05)$

Tabela 6. Teores foliares de nutrientes e metais pesados no período de cultivo da cana-planta e da cana-soca em função de doses de escória de siderurgia

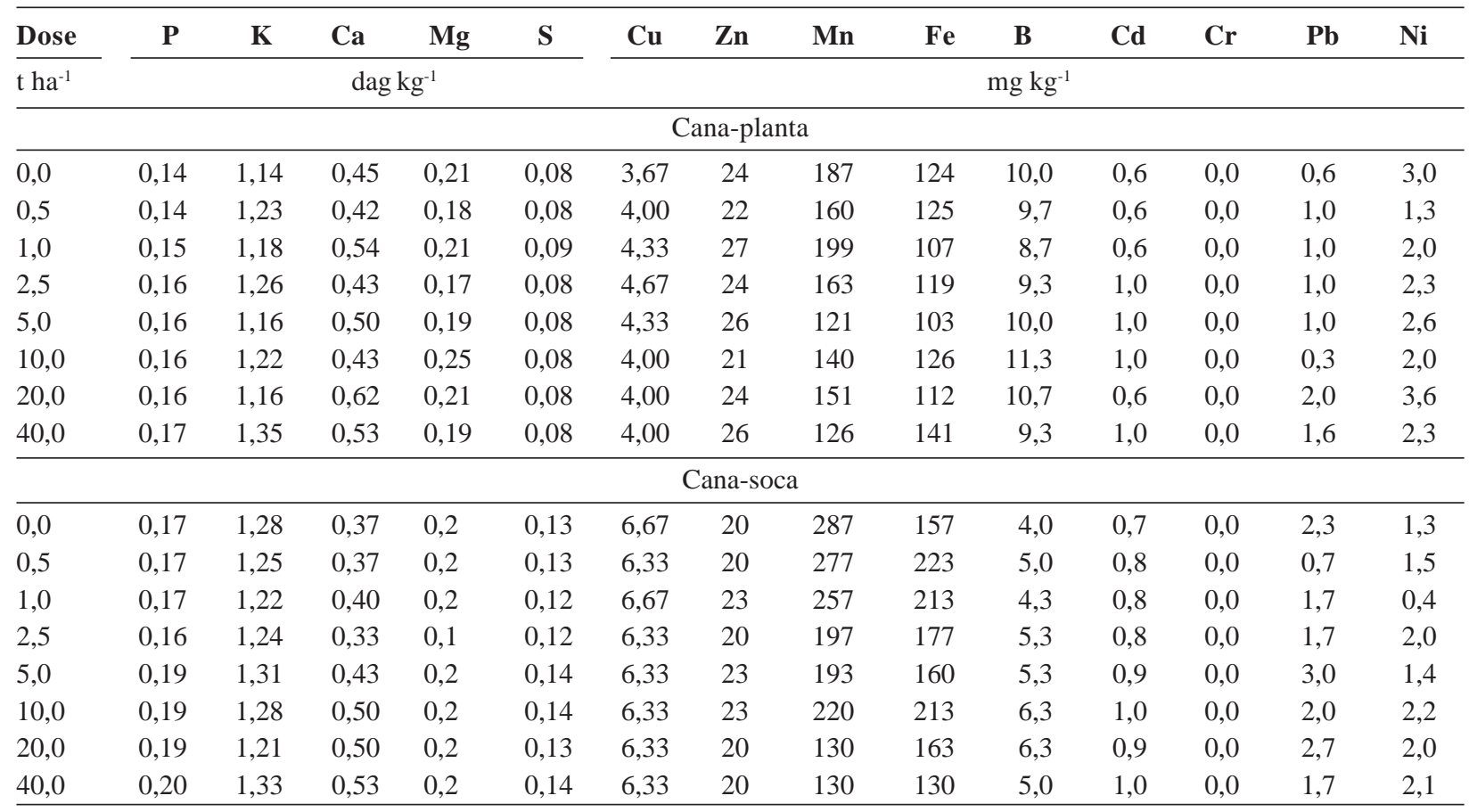

Rev. Ceres, Viçosa, v. 59, n.4, p. 530-536, jul/ago, 2012 
Tabela 7. Teores foliares de nutrientes e de metais pesados em função da dose de $2,5 \mathrm{t} \mathrm{ha}{ }^{-1}$ de escória de siderurgia e de calcário no período de cultivo da cana-planta e da cana-soca

\begin{tabular}{|c|c|c|c|c|c|c|c|c|c|c|c|c|c|c|}
\hline Dose & $\mathbf{P}$ & $\mathbf{K}$ & $\mathrm{Ca}$ & Mg & $\mathbf{S}$ & $\mathrm{Cu}$ & $\mathbf{Z n}$ & Mn & $\mathrm{Fe}$ & B & $\mathbf{C d}$ & $\mathrm{Cr}$ & $\mathbf{P b}$ & $\mathrm{Ni}$ \\
\hline$\overline{2,5 \mathrm{tha}^{-1}}$ & \multicolumn{5}{|c|}{ dag $\mathrm{kg}^{-1}$} & \multicolumn{9}{|c|}{$\mathrm{mg} \mathrm{kg}^{-1}$} \\
\hline \multicolumn{15}{|c|}{ Cana-planta } \\
\hline Escória & 0,16 & 1,26 & 0,43 & 0,17 & 0,08 & 4,7 & 24,7 & 163 & 119 & 9,3 & 1,3 & 0,0 & 1,1 & 2,3 \\
\hline Calcário & 0,15 & 1,32 & 0,42 & 0,18 & 0,08 & 4,3 & 22,7 & 144 & 124 & 9,3 & 1,4 & 0,0 & 1,2 & 2,7 \\
\hline \multicolumn{15}{|c|}{ Cana-soca } \\
\hline Escória & 0,16 & 1,24 & 0,33 & 0,11 & 0,12 & 6,33 & 20 & 197 & 177 & 8,2 & 0,8 & 0,0 & 1,7 & 2,6 \\
\hline Calcário & 0,17 & 1,28 & 0,38 & 0,24 & 0,13 & 7,00 & 23 & 257 & 163 & 8,4 & 0,9 & 0,0 & 3,3 & 2,3 \\
\hline
\end{tabular}

Não houve diferença significativa entre as médias das variáveis pelo teste de Dunnet $(\mathrm{P} \geq 0,05)$.

Tabela 8. Teores de nutrientes e de metais pesados no colmo da cana-planta em função de doses de escória de siderurgia

\begin{tabular}{|c|c|c|c|c|c|c|c|c|c|c|c|c|c|c|}
\hline \multirow{2}{*}{$\frac{\text { Dose }}{\text { t ha }^{-1}}$} & $\mathbf{P}$ & $\mathbf{K}$ & $\mathbf{C a}$ & Mg & $\mathbf{S}$ & $\mathrm{Cu}$ & $\mathrm{Zn}$ & Mn & $\mathrm{Fe}$ & B & Cd & $\mathrm{Cr}$ & $\mathbf{P b}$ & $\mathbf{N i}$ \\
\hline & \multicolumn{5}{|c|}{ dag $\mathrm{kg}^{-1}$} & \multicolumn{9}{|c|}{$\mathrm{mg} \mathrm{kg}^{-1}$} \\
\hline 0,0 & 0,010 & 0,31 & 0,07 & 0,06 & 0,06 & 2,00 & 5,7 & 76 & 46 & 6,0 & 5,3 & 0,0 & 3,3 & 4,3 \\
\hline 0,5 & 0,013 & 0,33 & 0,07 & 0,05 & 0,05 & 2,00 & 3,7 & 67 & 60 & 6,0 & 4,3 & 0,0 & 3,0 & 4,3 \\
\hline 1,0 & 0,010 & 0,23 & 0,07 & 0,06 & 0,06 & 2,00 & 5,3 & 70 & 40 & 5,0 & 5,3 & 0,0 & 2,7 & 6,0 \\
\hline 2,5 & 0,010 & 0,24 & 0,07 & 0,05 & 0,05 & 1,67 & 3,7 & 71 & 53 & 5,3 & 4,0 & 0,0 & 4,3 & 5,3 \\
\hline 5,0 & 0,017 & 0,37 & 0,09 & 0,07 & 0,07 & 2,00 & 4,7 & 57 & 52 & 5,3 & 5,0 & 0,0 & 2,0 & 3,7 \\
\hline 10,0 & 0,017 & 0,27 & 0,08 & 0,07 & 0,06 & 2,33 & 4,3 & 63 & 54 & 7,0 & 5,0 & 0,0 & 2,7 & 6,0 \\
\hline 20,0 & 0,017 & 0,34 & 0,08 & 0,07 & 0,06 & 2,00 & 3,3 & 45 & 41 & 5,3 & 5,0 & 0,0 & 2,0 & 5,0 \\
\hline 40,0 & 0,020 & 0,25 & 0,10 & 0,07 & 0,06 & 2,33 & 3,7 & 47 & 59 & 5,0 & 6,0 & 0,0 & 4,0 & 6,3 \\
\hline
\end{tabular}

elevação do pH do solo. Também não houve aumento significativo nos teores de metais pesados nos colmos da cana-de-açúcar. Este resultado é um importante indicativo de que o uso da escória, nessa cultura, mesmo em doses muito superiores às que seriam normalmente estimadas pelos métodos de recomendação de corretivos da acidez do solo, não ocasiona aumento dos teores de metais pesados na parte da planta utilizada para o consumo ou industrialização.

A escória promoveu aumento de produtividade tanto da cana-planta como da cana-soca (Figuras 1 e 2). Mesmo em doses elevadas, como as de 20 e $40 \mathrm{t} \mathrm{ha}^{-1}$ de escória,

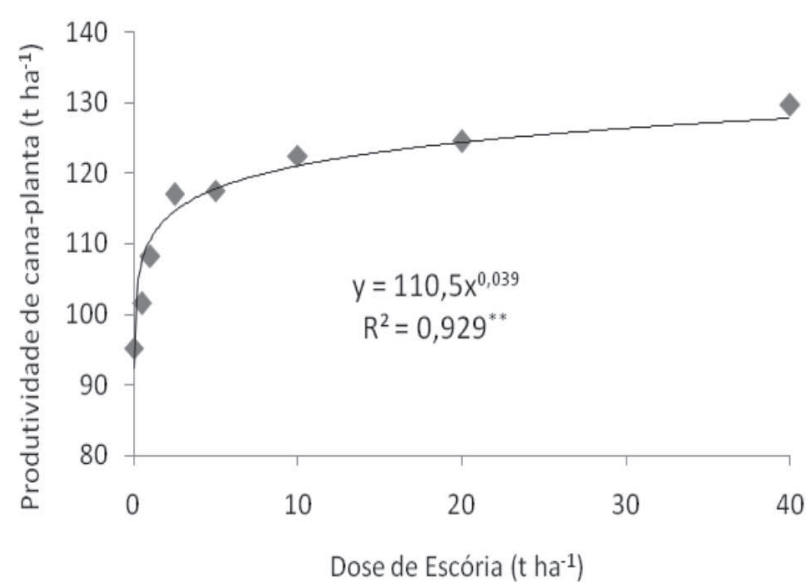

Figura 1. Produtividade de cana-planta em função de doses de escória. não se observaram decréscimos de produtividade nos dois cultivos.

Com base na função exponencial ajustada para a produtividade de cana-planta em função das doses de escória, observou-se que a maior curvatura ocorreu entre as produtividades de 110 e $120 \mathrm{t} \mathrm{ha}^{-1}$ (Figura 1). Considerando-se a média de $115 \mathrm{t} \mathrm{ha}^{-1}$, estima-se que a dose correspondente a esta produtividade foi de, aproximadamente, 3 t ha ${ }^{-1}$ de escória. Esta também é a dose que se situa próxima do ponto de maior curvatura da função exponencial ajustada para a produtividade de cana-soca (Figura 2).

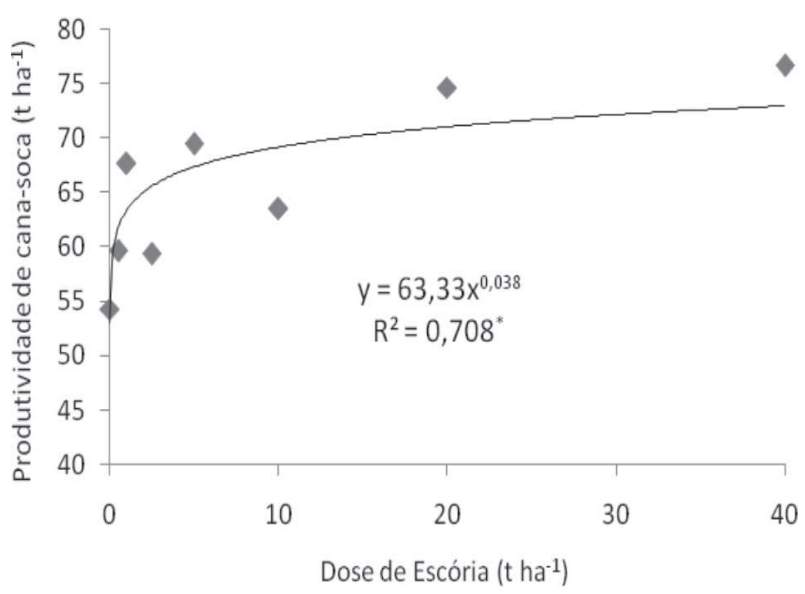

Figura 2. Produtividade de cana-soca em função de doses de escória.

Rev. Ceres, Viçosa, v. 59, n.4, p. 530-536, jul/ago, 2012 


\section{CONCLUSÕES}

A aplicação de escória no solo eleva o pH, a saturação por bases e os teores de P, Ca, B, Fe e Mn e de Mg.

Não há efeito significativo e consistente das doses de escória sobre os teores de metais pesados no solo.

Os teores de $\mathrm{P}$ e Ca na folha e no colmo da cana-deaçúcar aumentaram com as doses de escória, não havendo influência para os demais nutrientes, como, também, para os metais pesados.

Há elevação mais acentuada da produtividade, tanto da cana-planta como da cana-soca, até a dose de $3 \mathrm{t} \mathrm{ha}^{-1}$ de escória.

A escória de siderurgia pode ser utilizada como corretivo da acidez do solo e como fonte de alguns nutrientes, como o Ca e P, não havendo indicativo de elevação dos teores de metais pesados a níveis que possam comprometer a qualidade da cana-de-açúcar.

\section{AGRADECIMENTOS}

Ao técnico agrícola Pedro Henrique Cricco, pelo empenho na implantação e na condução do experimento, e à Arcelor Mittal Tubarão, pela cessão da escória utilizada neste trabalho.

\section{REFERÊNCIAS}

Abreu CA, Abreu MF, Raij B Van \& Santos WR (1995) Comparação de métodos de análise para avaliar a disponibilidade de metais pesados em solos. Revista Brasileira de Ciência do Solo, 19:463-468.

Alcântara MAK \& Camargo AO (2001) Fator de retardamento e coeficiente de dispersão-difusão para crômio (III) em solos muito intemperizados, influenciados pelo $\mathrm{pH}$, textura e matéria orgânica. Revista Brasileira de Ciência do Solo, 25:209-216.

Alcarde JC (1992) Corretivos da acidez dos solos: características e interpretações técnicas. São Paulo, ANDA. 26p. (Boletim Técnico,6).

Alvarez V VH \& Guarçoni MA (2003) Variabilidade horizontal da fertilidade do solo de uma unidade de amostragem em sistema plantio direto. Revista Brasileira de Ciência do Solo, 27:297310 .

Coelho PE (1998) Da escória ao vidro. Revista Limpeza Pública, 49:36-45.

Dias NM, Alleoni LRF, Casagrande JC \& Camargo AO (2001) Adsorção de cádmio em dois latossolos ácricos e um nitossolo. Revista Brasileira de Ciência do Solo, 25:297-304.

Empresa Brasileira de Pesquisa Agropecuária - Embrapa (1999) Manual de análise química dos solos, plantas e fertilizantes. Rio de Janeiro, Embrapa Solos. 370p.

Empresa Brasileira de Pesquisa Agropecuária - Embrapa (2009) Manual de análise química dos solos, plantas e fertilizantes. $2^{\mathrm{a} e d .}$ Brasília, Embrapa Solos. 627p.

Kabata-Pendias A \& Pendias H (1992) Trace elements in soil and plants. $2^{\mathrm{a}}$ ed. Boca Raton, CRC Press. 365p.
Mazur N (1997) Níquel, chumbo, zinco e cobre em solos que receberam compostos de resíduos sólidos urbanos. Tese de doutorado. Universidade Federal de Viçosa, Viçosa. 129p.

Prado RM \& Fernandes FM (1999) Efeito do calcário e da escória de siderurgia na disponibilidade de fósforo no Latossolo Verme1ho-Escuro e na Areia Quartzosa. Revista de Agricultura, 74:235242 .

Prado RM, Corrêa CM, Cintra ACO \& Natale W (2003) Resposta de mudas de goiabeira à aplicação de escória de siderurgia como corretivo de acidez do solo. Revista Brasileira de Fruticultura, 25:160-163.

Prado RM \& Fernandes FM (2000) Escória de siderurgia e calcário na correção da acidez do solo cultivado com cana-de-açúcar em vasos. Scientia Agricola, 57:739-744.

Prado RM \& Fernandes FM (2001) Efeito do escória de siderurgia e do calcário na disponibilidade de fósforo em um Latossolo Vermelh-Amarelo cultivado com cana-de-açúcar. Pesquisa Agropecuária Brasileira, 36:1199-1204.

Prado RM \& Fernandes FM (2003) Efeito residual da escória de siderurgia como corretivo da acidez do solo na soqueira da canade-açúcar. Revista Brasileira de Ciência do Solo, 27:287-296.

Prezotti LC, Gomes JÁ, Dadalto GG \& Oliveira JÁ (2007) Manual de Recomendação de calagem e adubação para o Estado do Espírito Santo $-5^{\circ}$ aproximação. Vitória, SEEA/Incaper/Cedagro. $305 \mathrm{p}$.

Ribeiro Júnior JI (2001) Análises estatísticas no SAEG. Viçosa, UFV. 301p.

Santos GCG dos, Abreu CA de, Camargo AO de \& Abreu MF de (2002) Pó-de-aciaria como fonte de zinco para o milho e seu efeito na disponibilidade de metais pesados. Bragantia, 61:257266.

Silva J da (2003) Avaliação do potencial agronômico e de contaminação ambiental decorrente do uso de uma escória de aciaria como corretivo e fertilizante de solos. Dissertação Mestrado. Universidade Federal de Viçosa, Viçosa. 134p. 